\title{
Study on the Mechanism and Simulation of the Hydraulic Fracture Propagation in the Argillaceous Unconsolidated
}

\section{Sandstone}

\author{
Zhang $\mathrm{W}^{1,2 *}$, Li N ${ }^{3}$, Ge $\mathrm{Y}^{2}$, Wang $\mathrm{X}^{4}$, Wang $\mathrm{Y}^{2}$ and Wang $\mathrm{X}^{4}$ \\ ${ }^{1}$ Key Laboratory of Unconventional Oil \& Gas Development (China University of \\ Petroleum (East China)), China \\ ${ }^{2}$ School of Petroleum Engineering, China University of Petroleum (East China), \\ China \\ ${ }^{3}$ CNPC Pipeline Bureau, China \\ ${ }^{4}$ China Oilfield Services Limited, China
}

\section{Research Article \\ Volume 3 Issue 5}

Received Date: September 03, 2019

Published Date: October 18, 2019

DOI: $10.23880 /$ ppej- 16000205

*Corresponding author: Weidong Zhang, Key Laboratory of Unconventional Oil \& Gas Development (China University of Petroleum (East China)), School of Petroleum Engineering, Qingdao 266580, P. R. China, Email: wdzhang@upc.edu.cn

\section{Abstract}

It is an urgent task to explore the development of argillaceous unconsolidated sandstone reservoir by hydraulic fracturing. Based on the physical parameters of the core, a physical simulation method is established and the fracturing test of argillaceous unconsolidated sandstone is carried out. Based on the analysis of the structure and physical properties of the argillaceous unconsolidated sandstone reservoir, the imitation method was established. With the increase of clay content, the hydraulic fracture was changed from the straight fracture to the fishbone seams which are in twists and turns with a seepage zone being tested. Based on the PFC discrete element method, the model of the argillaceous unconsolidated sandstone was established and the microscopic parameters were obtained. The fluid solid coupling was established. The simulation shows that the natural fractures are formed by the communication of the fracturing fluid, but the main fracture of the hydraulic fracturing was still extended along the direction of perpendicular to minimum principal stress. The smaller the difference between maximum principal stress and minimum principal stress was, the fracture was more Chaos. Through stress chain analysis, it was found that the stress direction is obvious, but the distribution of stress is very uneven. This phenomenon leads to shear stress in the process of crack propagation, which makes the hydraulic fracture more easily to divert branch fractures and produces broken zones.

Keywords: Argillaceous unconsolidated sandstone; Hydraulic fracturing; PFC numerical simulation 


\section{Petroleum \& Petrochemical Engineering Journal}

\section{Introduction}

According to clay content, the clay content of argillaceous unconsolidated sandstone is between $15 \% \sim 50 \%$. Traditionally, it is believed that the permeability of argillaceous unconsolidated sandstone is so low that it is difficult to regard as an industrial oil and gas reservoir [1]. However, with the high development of high quality oil and gas reservoirs, people have to turn their development targets to inferior oil and gas reservoirs, such as the argillaceous sandstone reservoir. Hydraulic fracturing technology has played a great role in conventional low permeability oilfield and unconventional oil \& gas reservoirs [2]. It is becoming more and more urgent for us to exploit argillaceous unconsolidated sandstone reservoir by hydraulic fracturing.

Cundall [3] puts forward the concept of discrete element, which regards the discontinuity as collection of discrete elements. The elements are connected through the contact points, and each element is iteratively solved through the motion equation. Yizhong Zhao, et al. [4] carried out numerical simulation analysis of fluid solid coupling of unconsolidated sandstone. Weizhang Wang, et al. [5] studied the fracture characteristics of unconsolidated sandstone strata through PFC. Zhilong Lian, et al. [6] studied the law of rock mechanics parameters on crack initiation and propagation by numerical simulation. Zhihua Zhang, et al. [7] simulated the coarse grained soil through PFC software. Xianshan Liu, et al. [8] analyzed the sand production mechanism of oil well by fluid solid coupling method through PFC software. Gil IR, et al. [9] established unconsolidated sandstone model through PFC software, and studied the influence of model parameters on mechanical properties of rock samples. Ming $X$ [10] simulated the triaxial fracturing of brittle rock by PFC, and get the fitting results with experiment. Sarmadivaleh M, et al. [11] carried out hydraulic fracturing simulation of sandstone through PFC. $\mathrm{Xu} \mathrm{B}$, et al. [12] used discrete element to simulate hydraulic fracturing process, and conducted fluid structure interaction analysis. However, no research has been done on argillaceous unconsolidated sandstone. In this paper, the fracture propagation law is revealed through fracturing experiments in argillaceous unconsolidated sandstone, and the fracture propagation mechanism of fractured argillaceous unconsolidated sandstone is studied by PFC simulation.
PFC (Particle flow code) is a discrete element method for rock mechanics numerical simulation. In PFC modeling, the discrete particles are cemented by contact just like the discrete system of argillaceous unconsolidated sandstone, in which sands are weakly cemented by argillaceous [13]. Fluid flow happens in the pipeline network formed by porosity of particle assembles [14]. When the stress exceeds the strength of a contact between two particles, then the contact is destroyed and a fracture occurs [15].

\section{Hydraulic Fracturing Test of Argillaceous Unconsolidated Sandstone}

\section{Imitation of Argillaceous Unconsolidated Sandstone Core}

A X ray diffractometer is used to analyze the whole rock mineral of a argillaceous unconsolidated sandstone core. The rock is mainly composed of quartz and clay minerals, in which the quartz content about $50 \%$ of the total rock mass and the clay mineral is $19 \% \sim 34 \%$. The porosity of core is $24.4 \%$, permeability is $27 \times 10^{-3} \mu \mathrm{m}^{2}$, uniaxial young's modulus is $440 \mathrm{MPa}$, uniaxial compressive strength is $6 \mathrm{MPa}$, Poisson's ratio is 0.31 .

According to the mass ratio of sand particles: Clay: water equal to 30:8:2, adjusting the amount of cementing agent and pressing pressure to make $\phi 25 \mathrm{~mm}$ cylinder cores with different physical parameters, the rock physical and mechanical parameters are tested. The test result is closest to the core of the field sample as the selective parameter. The selective parameter is the mass ratio of sand particles: Clay: cementing agent: water equal to $30: 8: 2: 2$, pressure $20 \mathrm{MPa}$. This core's porosity is $23.28 \%$, permeability is $27.4 \times 10-3 \mu \mathrm{m} 2$, uniaxial Yang's modulus is $495.3 \mathrm{MPa}$, uniaxial compressive strength is $6.663 \mathrm{MPa}$, Poisson ratio is 0.3294 , that is similar to the underground rock。 This core is 14\# sample later.

\section{Hydraulic Fracturing Test of Argillaceous Unconsolidated Sandstone Sample}

According to the above imitation core formula, the rock mass ratio of sandstone is adjusted to make $0.5 \mathrm{~m}$ cubic rock samples, and the small casing with holes is prefabricated into the rock heart in advance. The clay content of $5 \#$ and $6 \#$ is $23.8 \%, 7 \#$ is $19.5 \%$, and $8 \#$ is $28.6 \%$.
Zhang W, et al. Study on the Mechanism and Simulation of the Hydraulic Fracture Propagation in the Argillaceous Unconsolidated Sandstone. Pet Petro Chem Eng J 2019, 3(5): 000205. 


\section{Petroleum \& Petrochemical Engineering Journal}

In this study, the real triaxial hydraulic fracturing simulation test system of the China University of Petroleum (Hua Dong) and the Mechanical Laboratory of the College of construction and engineering is used in the large size core making and simulation fracturing experiments. The structure is shown in Figure 1.

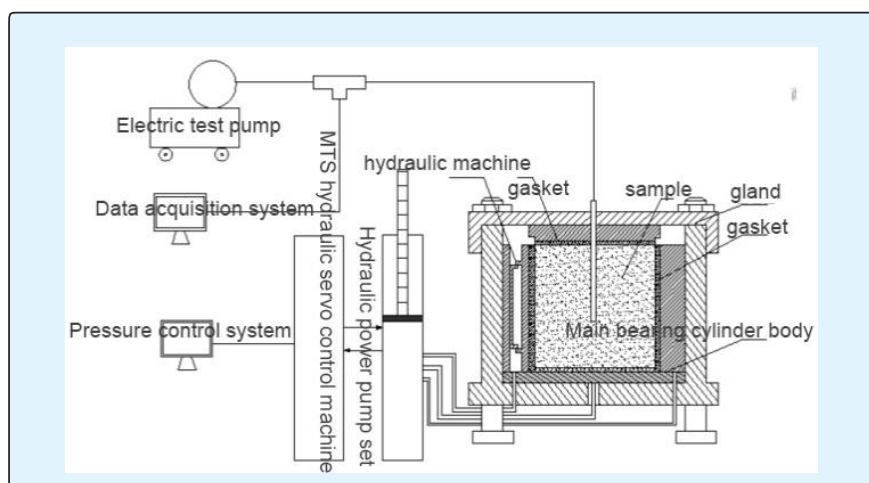

Figure 1: Schematic diagram of fracturing equipment structure.

During the test, we put the rock sample into the test device and then loaded the triaxial pressure. Vertical stress is $10 \mathrm{MPa}$, the maximum horizontal principal stress is $9 \mathrm{MPa}$ and the minimum horizontal principal stress $8 \mathrm{MPa}$. After loading, the fracturing fluid is pumped from the simulated wellbore until the pressure monitoring software shows that the pressure suddenly drops, and the rock sample is fractured effectively. The rock samples were taken for observation and dissection. So far, a group of experiments were completed.

\section{Hydraulic Fracturing Test Results}

In the hydraulic fracturing test under the same triaxial pressure, 5\# produced a one-winged vertical main fracture perpendicular to the minimum principal stress, and there were micro cracks on both sides of the main fracture. 6\# produced double-winged vertical main fracture perpendicular to the minimum principal stress. After fracturing, 7\# appeared multiple fractures by CT scan, and produced double-winged vertical main fracture perpendicular to the minimum principal stress, and produced a branch fracture on the side. 8\# produced double-winged vertical main fracture perpendicular to the minimum principal stress, and there were micro cracks on both sides of main fracture (Figures 2-5).

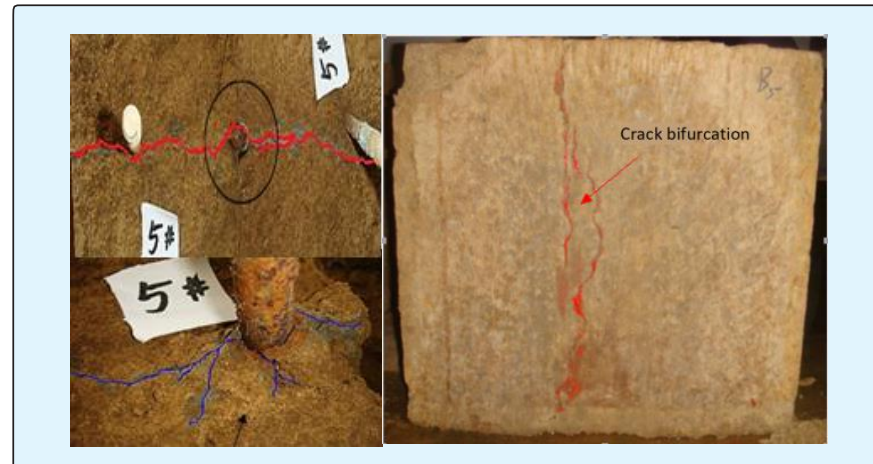

Figure 2: Fracture morphology of specimen 5\#.
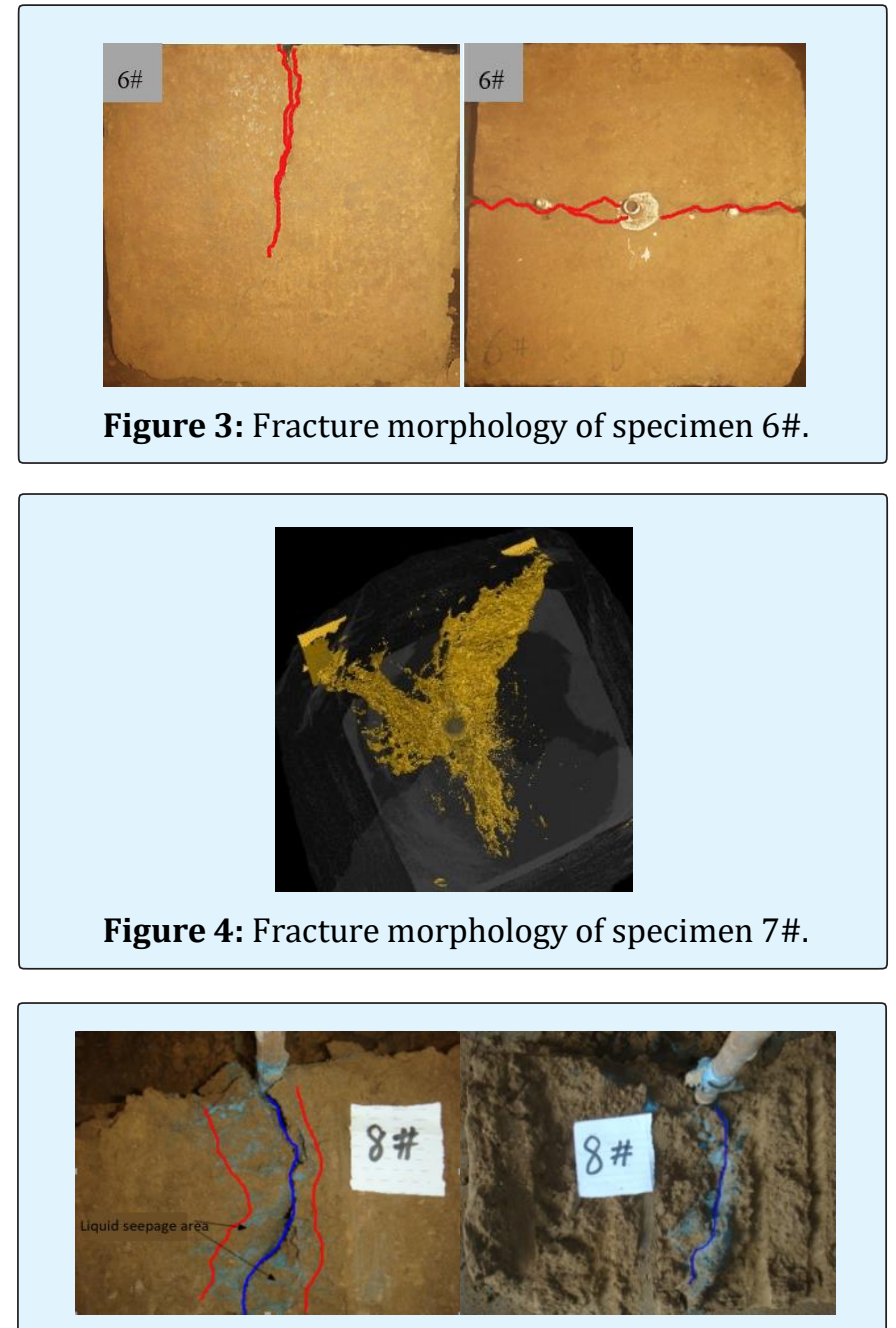

Figure 5: Fracture morphology of specimen 7\#. 


\section{Petroleum \& Petrochemical Engineering Journal}

\section{Modeling of Argillaceous Unconsolidated Sandstone based on PFC Discrete Element Method}

The unconsolidated sandstone has a poor cementation degree under simple sedimentary environment, and its rock mass structure discontinuity is more obvious. Especially when clay is used as cementing material, its mechanical properties are quite different from those of sandstone particles, and structural discontinuity is more prominent. The discrete element theory is more suitable for the unconsolidated sandstone than the conventional method, and it can get more accurate prediction results. In this regard, PFC discrete element is applied to numerical simulation of hydraulic fracturing of argillaceous unconsolidated sandstone.

\section{Mechanical Experiment Fitting}

The 14\# sample core is the closest to the actual reservoir. For further prediction, $\mathrm{PFC} 3 \mathrm{D}$ is used to fit the results of uniaxial fracturing of rock samples and determine the parameters of numerical simulation.

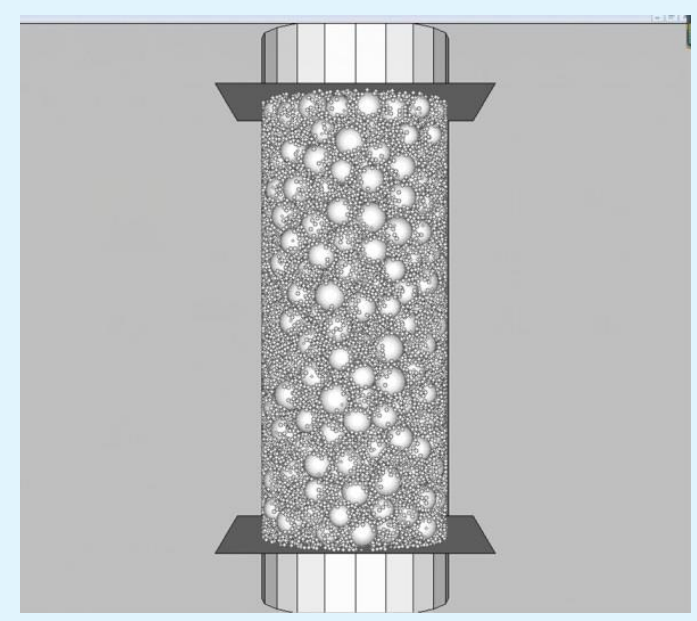

Figure 6: Compaction of particles and walls.

This core's composition can be divided into two parts, one is sand particles and the other is cement. The sand particles' diameter is $30 \mu \mathrm{m}$. Cement is a mixture of clay and epoxy resin and its particle' diameter is $5 \mu \mathrm{m}$. The generated particles are surrounded by three walls and compacted. One wall is cylindrical shape, the other two walls are straight panel shape, as shown in Figure 6.

Zhang W, et al. Study on the Mechanism and Simulation of the Hydraulic Fracture Propagation in the Argillaceous Unconsolidated Sandstone. Pet Petro Chem Eng J 2019, 3(5): 000205.

\begin{tabular}{|c|c|c|c|c|c|c|}
\hline parameter & $\begin{array}{c}k n \\
/ \mathrm{MPa}\end{array}$ & $\begin{array}{c}k s \\
/ \mathrm{MPa}\end{array}$ & $\begin{array}{c}b_{-} k n \\
/ \mathrm{MPa}\end{array}$ & $\begin{array}{c}P b_{-} k s \\
/ \mathrm{MPa}\end{array}$ & $\begin{array}{c}\sigma_{\mathrm{n}} \\
/ \mathrm{MPa}\end{array}$ & $\begin{array}{c}\sigma_{\mathrm{s}} \\
/ \mathrm{MPa}\end{array}$ \\
\hline Sandstone & 300 & 300 & 9000 & 6000 & 20 & 10 \\
\hline mudstone & 6 & 2 & 12 & 8 & 0.12 & 0.06 \\
\hline
\end{tabular}

Table 1: PFC modeling parameters of argillaceous unconsolidated sandstone.

When the ball is generated, the wall is compacted $20 \mathrm{MPa}$ according to the actual experimental pressure, and given the parallel bonding model after compacted. The model parameters are shown in Table $1 . \mathrm{kn}$ and ks are normal stiffness and tangential stiffness of particles, respectively. $\mathrm{Pb} \_\mathrm{kn}$ and pb_ks are particle parallel bonding normal stiffness, parallel bonding tangential stiffness, respectively. $\sigma_{n}$ is normal strength and $\sigma_{s}$ is tangential strength.

After the establishment of the model, the operation of the $10^{-5} \mathrm{~m}$ distance at each step is carried out, and the upper \& lower two walls are loaded until the uniaxial strain of the core reaches 0.03 . The fracture form comparison between the numerical core and the actual core after the uniaxial mechanical experiment of rock is shown in Figure 7.

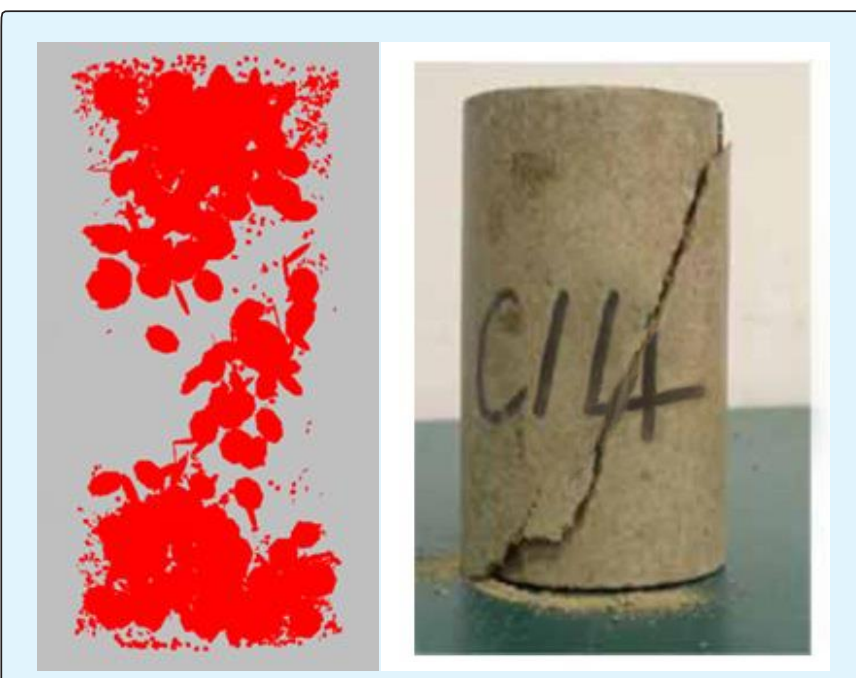

Figure 7: Comparison of numerical and actual uniaxial experiment.

\section{PFC Modeling of Hydraulic Fracturing in Argillaceous Unconsolidated Sandstone}

On the basis of hydraulic fracturing test of argillaceous unconsolidated sandstone, numerical simulation of 


\section{Petroleum \& Petrochemical Engineering Journal}

hydraulic fracturing experiment is carried out by numerical simulation of rock sample data obtained by uniaxial fracturing core.

The 4 walls with $30 \mathrm{~mm}$ length square are built into a cube, and the stiffness is 15 times of the particle stiffness. Then particles are generated according to the ratio of sandstone to mudstone volume equal to $3: 1$. The size of the particles is still $30 \mu \mathrm{m}$ with sandstone and $5 \mu \mathrm{m}$ with mudstone. By loading stress, the maximum horizontal principal stress is $10 \mathrm{MPa}$ and the minimum horizontal principal stress is 8MPa. After modeling, the rock mechanics parameters measured in uniaxial fracturing are given. Then the fluid solid coupling programming is carried out for the model. Then, the hydraulic pressure of $12 \mathrm{MPa}$ is applied to $1 \mathrm{~mm}$ at the distance from the center point to XY direction. The result is shown in Figure 8, where the blue box area is the injection area of fracturing fluid, and the red crack is hydraulic fracture. It can be seen from the diagram that hydraulic fracturing forms fractured zones in rock samples, and the initiation cracks are rather tortuous. The effect of actual fracturing is fitted.

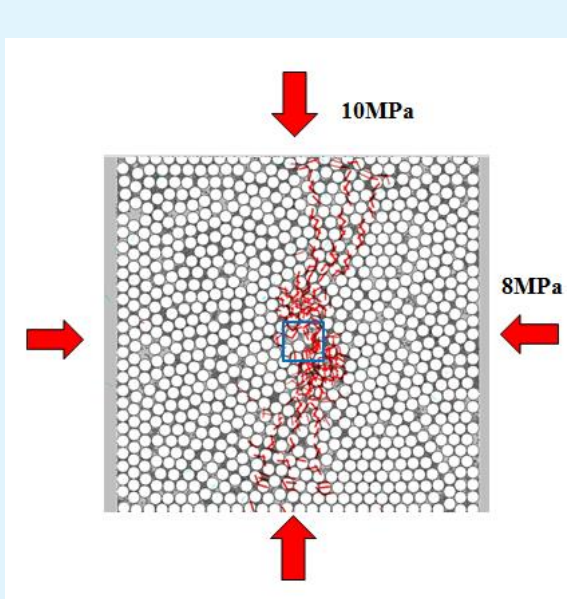

Figure 8: Effect diagram of hydraulic fracture by PFC.

\section{Numerical Simulation Prediction and Analysis of Hydraulic Fracturing in Argillaceous Unconsolidated Sandstone Reservoir}

On the basis of previous tests, parameters and rock mechanics parameters of rock samples have been obtained, and the test results have been fitted. In the actual strata, there are different clay content, different natural fractures and different geostress. All these need further be researched.

\section{Prediction of Hydraulic Fracture Propagation Under Natural Fracture Distribution}

In addition to the main fracture perpendicular to the minimum principal stress, the $7 \#$ rock also produces a branch joint with a lateral side. Guessing that the natural crack exists before the hydraulic fracturing experiment. In the experiment, the natural crack will continue to expand the branch joints while forming the main fracture perpendicular to the minimum main stress.

In PFC software, the discontinuity is added at any direction through instructions, and the mechanical properties of discontinuity are specified. By specifying the strength of discontinuity as normal strength $0.5 \mathrm{MPa}$ and tangential strength $0.5 \mathrm{MPa}$, a natural crack which is $60^{\circ}$ of the maximum principal stress direction is set up.

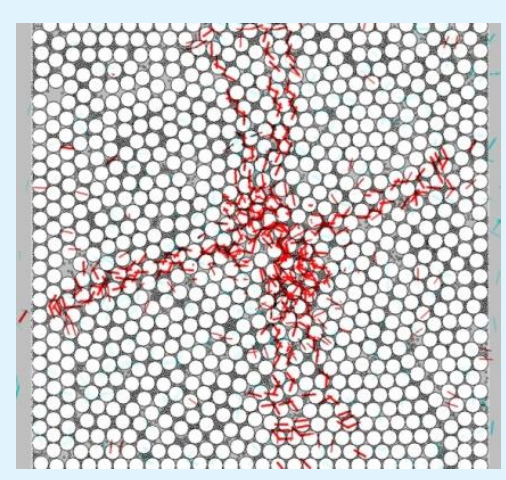

Figure 9: Simulation of the effect of natural fractures on the fracture morphology of hydraulic fracturing.

The numerical simulation shows that when there is a natural crack in the unconsolidated sandstone, it extends along natural fractures and does not affect the formation of the main seam along the direction of the maximum principal stress, such as Figure 9.

\section{Prediction of Hydraulic Fracture Propagation under Different Stress Differences}

The relationship between hydraulic fracturing and stress field is very close. Under different stress fields, the shape and the degree of opening and closing of hydraulic fracturing are different. In order to analyze the rule of 


\section{Petroleum \& Petrochemical Engineering Journal}

crack propagation under different stress difference, four kinds of geostress field are set up to compare the results. The applied overburden pressure is $10 \mathrm{MPa}$, and the two horizontal principal stress values are shown in Figure 10. The corresponding stress difference is $0 \mathrm{MPa}, 1 \mathrm{MPa}, 2 \mathrm{MPa}$ and $3 \mathrm{MPa}$.

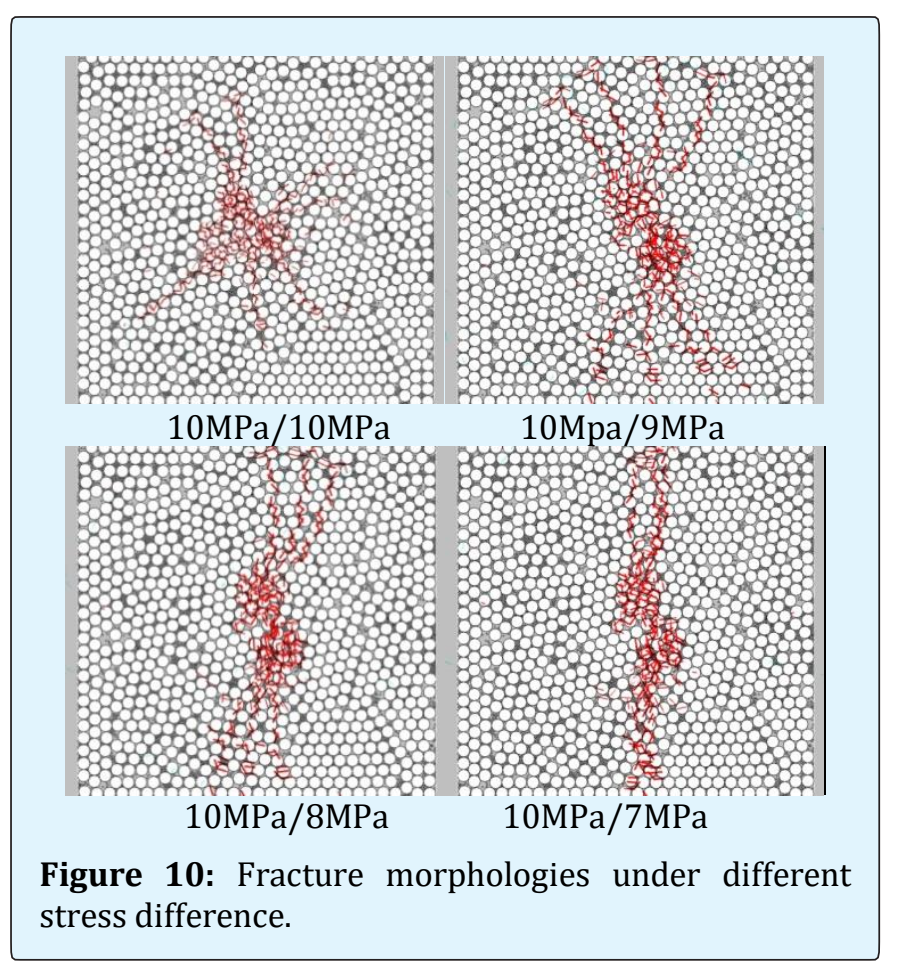

According to the analysis of the fracturing simulation results under the different stress difference above, it can be obtained that, under the condition of the stress difference of 0 , the rock sample forms a broken zone near the wellbore, and the extension and Chaos of the cracks are irregular and cannot form a straight and effective diversion crack. When the stress difference is $1 \mathrm{MPa}, 2 \mathrm{MPa}$ and $3 \mathrm{MPa}$, an effective diversion channel can be formed. With the increase of stress difference, the hydraulic fracture is transformed from a disordered fracture zone to a straight diversion crack, as shown in Figure 10.

\section{Stress Chain Analysis}

In the argillaceous unconsolidated sandstone, the degree of compaction is low, the degree of cementation is poor, and the homogeneity of formation is relatively poor. Clay fills in the blanks resulting in uneven mechanical properties of strata and a great difference in compressive capacity. Therefore, it is very necessary to study the distribution of internal stress under the condition of insitu stress loading in unconsolidated sandstone.

In PFC, model A and model $\mathrm{B}$ are established respectively, in which model $\mathrm{A}$ is cemented by pure unconsolidated sandstone, and model B is the argillaceous unconsolidated sandstone stratum studied. The stress of $10 \mathrm{MPa} / 8 \mathrm{MPa}$ is also loaded on the two directions, and the stress chain distribution is observed.

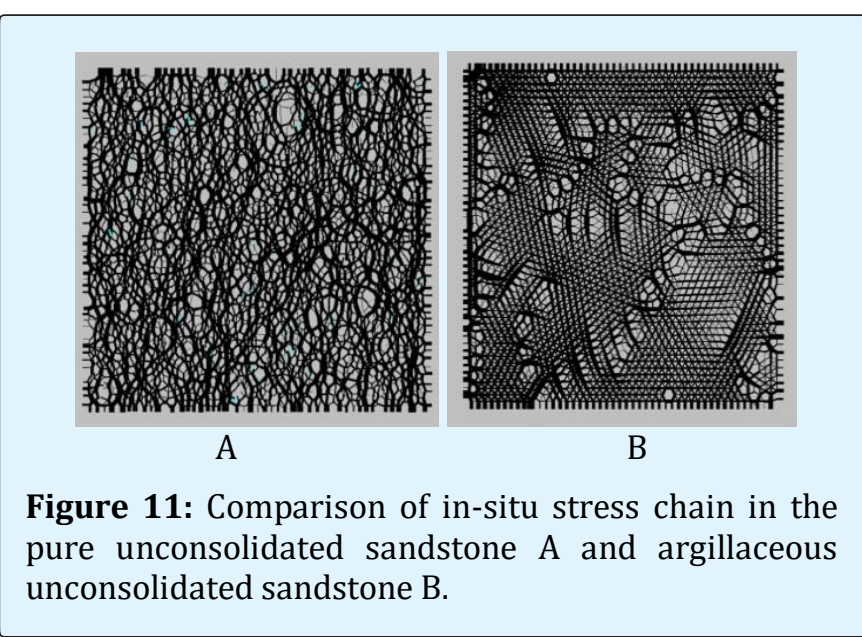

The size of the stress chain is characterized by the thickness of the stress chain. It can be observed that the stress chain on the pure unconsolidated sandstone is more obvious and uniform. However, the stress chain on the argillaceous unconsolidated sandstone is very uneven in Figure 11. Both fracture shapes simulated are also quite different. The hydraulic fractures of sandstone are straight. The hydraulic fractures of argillaceous unconsolidated sandstone are rough with certain fracture zones.

\section{Analysis of Microscopic Parameters of Failure Curves}

Compared with pure unconsolidated sandstone, the strength of argillaceous unconsolidated sandstone is lower, the elastic modulus is smaller, Poisson is bigger, and plasticity is more obvious. As reflected on the microscopic parameters, while the values of stress strength are lower, $\sigma_{n}$ and $\sigma_{s}$ are smaller. While the smaller the modulus of elasticity is, the smaller the values of Kn and Ks are. The larger Poisson's ratio the smaller $K n / K s$ is. The obvious plasticity the larger $\sigma_{n} / \sigma_{s}$ is. The PFC software analysis shows that the external force makes the particles displace each other. When the 


\section{Petroleum \& Petrochemical Engineering Journal}

distance between the particles exceeds the critical value, the cementation between particles is destroyed. In the case of stress, tension failure occurs when $\sigma_{\max }>\sigma_{n}$, and shear failure occurs when $\tau_{\max }>\sigma_{s}$. The two factors, such as large Poisson's ratio and large plasticity, are easy to cause shear failure of particles and thus cause fracture zones.

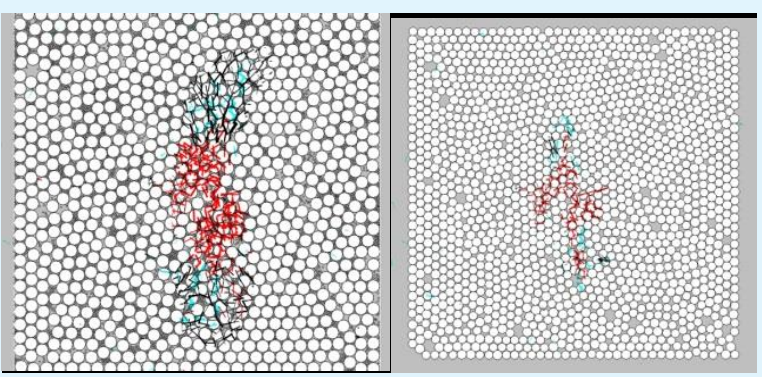

Figure 12: Failure mode analysis of crack growth.

The black strip represents shear force, and the blue strip represents tensile stress. It can be observed that in the fracturing process of the argillaceous unconsolidated sandstone formation, the tensile stress is the main point of the fracture, and the shear zone is easy to form on the two wings of the fracture. And the fracture tip of sandstone stratum is tensile tension, and the shear force is relatively less, as shown in Figure 12.

\section{The Influence of Stress Distribution on the Form of Failure}

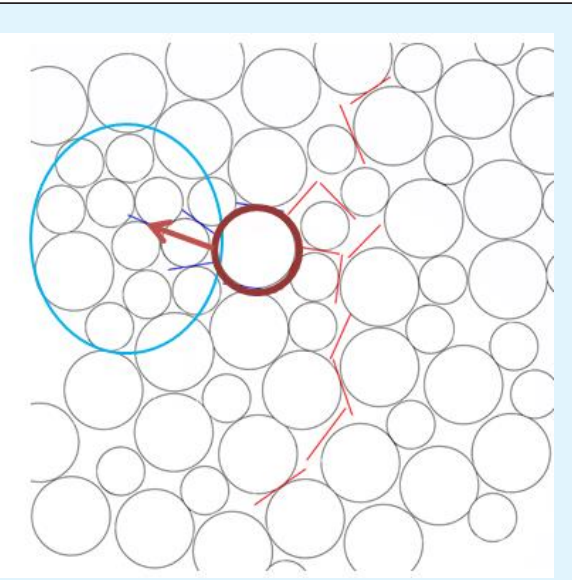

Figure 13: Shear failure caused by uneven stress distribution.
The shear failure caused by uneven stress distribution is shown in Figure 13. The blue trap area is the concentrated part of compacted uneven mudstone. This part is soft and can't form effective support for the red ball. Under the action of hydraulic fracturing, the cementation up and down of the red ball is destroyed and formed shear joints under the action of shear force.

\section{Conclusion}

1. Hydraulic fracturing experiments on the core of the argillaceous unconsolidated sandstone indicate that the clay content has a significant effect on the hydraulic fracture morphology of the argillaceous unconsolidated sandstone. With the increase of clay content, the plasticity of rock sample is bigger and bigger, and the opening of cracks is smaller and smaller. The form of cracks is more and more curved, showing plume branches.

2. The numerical simulation of PFC shows that under the action of geostress, the existing natural cracks will be communicated by the fracturing fluid under the hydraulic pressure, forming a branch crack. However, the main fracture of hydraulic fracturing still extends along the direction perpendicular to the minimum principal stress. The in-situ stress field will obviously affect the form of hydraulic fracture in argillaceous unconsolidated sandstone. The smaller the stress difference, the more fractured zone will be formed. The larger the stress difference, the more straight the hydraulic fracture is.

3. Through the analysis of the stress chain of simulated stratigraphy through the PFC software, it is found that the stress chain is obvious and the stress distribution is uniform after loading stress field of the homogeneous sandstone. After loading stress field of argillaceous unconsolidated sandstone, the direction of stress chain is very obvious, but the stress distribution is very serious. This phenomenon causes the shear stress in the argillaceous unconsolidated sandstone formation, which makes the hydraulic fracture easier to turn to the branch and produce the fracture zone.

4. The analysis of the microscopic parameters of the failure form shows while the ratio of the shear stiffness to the normal stiffness is bigger, Poisson' ratio is bigger. While the ratio of the shear strength to the normal strength is larger, the plasticity is larger. Therefore, the shear force generated by clay rock is more likely to exceed shear strength, resulting in shear failure. Uneven distribution of stress caused by uneven compaction is also the reason for shear failure in
Zhang W, et al. Study on the Mechanism and Simulation of the Hydraulic Fracture Propagation in the Argillaceous Unconsolidated Sandstone. Pet Petro Chem Eng J 2019, 3(5): 000205. 


\section{Petroleum \& Petrochemical Engineering Journal}

argillaceous unconsolidated sandstone formations.

\section{Acknowledgment}

This research is supported by the National Natural Science Foundation of China (Project No. 51374229) and Shandong Natural Science Foundation (Project No. ZR2019MEE101).

\section{References}

1. Shi Y, Yang W, Qian Z (1996) Basic geology of Petroleum University Press. pp: 133-135.

2. Rahim Z, Al-Anazi H, Al-Kanaan A (2012) Productivity increase using hydraulic fracturing in conventional and tight gas reservoirs-expectation versus reality. Society of Petroleum Engineers, pp: 13.

3. Cundall PA (1971) The Measurement and Analysis of Acceleration in Rock Slopes [D]. University of London, Imperial College of Science and Technology.

4. Zhao Y (2008) Numerical simulation of deliverability, fracturing and deliverability and fluid solid coupling in unconsolidated sandstone reservoir [D]. China University of Petroleum (Hua Dong).

5. Wang W (2008) Theory and engineering application of high-pressure compaction gravel packing for unconsolidated sandstone [D]. China University of Petroleum (Hua Dong).

6. Lian Z, Zhang J, Wang X, et al. (2009) Numerical simulation of hydraulic fracturing expansion characteristics. Geotechnical mechanics 30(1): 169174.

7. Zhang Z (2015) Meso numerical simulation of three axis test for coarse grained soil based on PFC3D [D]. China Three Gorges University.
8. Liu X, Ming Xu (2013) Meso mechanism of sand production in oil wells based on three-dimensional fluid solid coupling model. Geotechnical mechanics 34(8): 2363-2370.

9. Gil IR, Hart R, Roegiers JC, Shimizu Y (2005) Considerations on hydraulic fracturing of unconsolidated formations. Impact of Human Activity on the Geological Environment.

10. Ming X, Keping Z, Baoping Z (2009) Experimental study and PFC modelling of failure process of brittle rock under uniaxial compression [C]. The 43rd US Rock Mechanics Symposium, ARMA 09-29.

11. Sarmadivaleh M, Rasouli V, Ramses W (2012) Numerical simulations of hydraulic fracture intersecting an interbed of sandstone [C]. Harmonising Rock Engineering and the Environment, ISRM-12CONGRESS-2011-197.

12. Xu B, Wong RCK (2010) A 3D finite element model for history matching hydraulic fracturing in unconsolidated sands formation 49(4): 58-66.

13. American Rock Mechanics Association (2014) An Integrative Numerical Modeling Framework for Attacking Sand Production Problem [C]. The $48^{\text {th }}$ US Rock Mechnics/Geomechanics Symposium.

14. Wenjing Li, Rui Wu (2016) Geomechanical Evaluation for Previously Fractured Unconsolidated Formation in Microscopic Numerical Modeling [C]. International Petroleum Technology Conference, Thailand.

15. Experimental and Numerical Investigation of the Effect of Inner and Outer Boundary Dimensions on Collapse of the Sample in Thick-Walled Cylinder Test [C]. 51st US Rock Mechanics. 